\title{
CORRENTES IÔNICAS, INDUZIDAS POR ATP, EM CÉLULAS DE LEYDIG
}

\author{
IONIC CURRENTS INDUCED BY ATP IN LEYDIG CELLS
}

Endrigo P. Pontelli'; José F. Aguiar² \& Wamberto A. Varanda ${ }^{3}$

\begin{abstract}
${ }^{1}$ Aluno de Iniciação Científica;'Técnico Especializado;'Docente. Departamento de Fisiologia. Faculdade de Medicina de Ribeirão Preto - USP. CorRespondêncIA: Wamberto A. Varanda. Departamento de Fisiologia. Faculdade de Medicina de Ribeirão Preto-USP. Av. Bandeirantes, 3900. 14049-900 Ribeirão Preto, São Paulo, Brasil. Fone (16) 602-3024. Fax (16) 633-0017. e-mail: wvaranda@fmrp.usp.br; endrigo@rfi.fmrp.usp.br
\end{abstract}

PONTELLI EP; AGUIAR JF \& VARANDA WA. Correntes iônicas, induzidas por ATP, em células de Leydig. Medicina, Ribeirão Preto, 33: 136-140, abr./jun. 2000.

RESUMO: As células de Leydig produzem e secretam testosterona, num processo controlado pelo Hormônio Luteinizante $(\mathrm{LH})$ e modulado através de diversos fatores. $\mathrm{O}$ trifosfato de adenosina (ATP), no meio extracelular, tem se constituído num novo modulador do processo, atuando via ativação de receptores purinérgicos. Neste trabalho, a técnica de "patch-clamp" foi utilizada para detectar e caracterizar as correntes iônicas, induzidas pela ativação desses receptores, em células de Leydig, isoladas a fresco, de testículos de camundongos. A adição de ATP ao banho levou ao surgimento de uma corrente orientada para dentro, em potenciais hiperpolarizantes. A amplitude da corrente é dependente da dose de ATP, para cada nível de potencial aplicado à célula, e apresenta dessensibilização para doses acima de $60 \mu \mathrm{M}$. A relação corrente-voltagem é fortemente retificada na direção de potenciais hiperpolarizantes e apresenta um potencial de reversão próximo de zero $\mathrm{mV}$, indicando uma via de baixa seletividade a cátions. Esses resultados vêm confirmar a presença de receptores purinérgicos em células de Leydig, muito provavelmente pertencentes à família P2X.

UNITERMOS: Adenosina Trifosfato. Receptores Purinérgicos. Técnicas de Patch-Clamp. Células de Leydig.

\section{1- INTRODUÇÃO}

As células de Leydig produzem e secretam testosterona em mamíferos, sendo controladas essencialmente pelo hipófise, via Hormônio Luteinizante (LH). Várias substâncias regulam o processo, havendo evidências recentes de que o ATP também atuaria como modulador do mesmo ${ }^{(1)}$.

Classicamente, o ATP é tido como de importância fundamental em muitos processos intracelulares, como no metabolismo energético, na síntese de ácidos nucléicos e na regulação de atividades enzimáticas.
Uma nova função para essa molécula seria a de atuar, também, como hormônio, secreção autócrina ou parácrina, agindo em receptores específicos de membrana, e, portanto, a partir do meio extracelular. O primeiro a sugerir isso foi Burnstock ${ }^{(2)}$, baseado em observações onde o ATP, ou moléculas resultantes do seu catabolismo, como o difosfato de adenosina (ADP) ou adenosina, induziam algum tipo de sinalização em junções sinápticas, que ele denominou de transmissão NANC (Não-Adrenérgica Não-Colinérgica). Esse efeito se faria através da ligação das moléculas a receptores específicos, que ele denominou de "receptores 
purinérgicos", e reconhecidamente presentes em vários tipos celulares. Com base em suas propriedades farmacológicas e moleculares, os receptores purinérgicos têm sido agrupados em duas grandes famílias ${ }^{(3)}$ : a P2X (canais iônicos, ativados por ligantes) e a P2Y (receptores de membranas, acoplados à proteína $\mathrm{G}$ ). Dentro de uma mesma família, os subtipos seriam numerados em ordem crescente conforme fossem sendo clonados.

Em células de Leydig de ratos, Foresta et al. ${ }^{(1)}$ verificaram que o ATP induz um aumento na produção e secreção de testosterona de forma dependente da dose e do tempo de incubação. Os efeitos máximos observados ocorriam com uma concentração de ATP de $100 \mu \mathrm{M}$ e após um tempo de incubação de três horas. Esse fenômeno é subseqüente a um aumento na concentração intracelular de cálcio, recrutado tanto de estoques intracelulares como do meio extracelular. Resultados semelhantes foram descritos para células de Leydig de camundongos, em 1996, por PerezArmendariz et al., que observaram, ainda, ser o efeito do ATP inibido por suramina ${ }^{(4)}$. Neste trabalho, utilizamos a variante "whole cell" da técnica de "patch clamp" para detectar e caracterizar as correntes iônicas induzidas pelo ATP em células de Leydig de camundongos. Nossos resultados demonstram que o ATP induz uma corrente com forte retificação em potenciais hiperpolarizantes, carreada esssencialmente por cátions. Essa corrente apresenta um potencial de reversão ao redor de zero $\mathrm{mV}$, sugerindo que a via de permeação não discrimina entre os vários cátions presentes no meio intra e extracelular. Tais correntes são bloqueadas por suramina. Esses achados sugerem que os receptores presentes nessas células sejam do tipo P2X.

\section{2- MATERIAIS E MÉTODOS}

\subsection{Células}

Os experimentos foram realizados em células de Leydig de camundongos suiços, com idade ao redor de 45 dias. As células foram isoladas, mecanicamente, por processos de injeção/sucção, com o auxílio de uma seringa e agulha, contendo solução de Hank ${ }^{(5)}$. Após serem semeadas sobre lamínulas de vidro, onde aderem, as células são transferidas para uma câmara de acrílico, de volume aproximado de $300 \mu \mathrm{L}$, montada sobre a platina de um microscópio de fase, invertido (Nikon-TMD) para a realização dos registros eletrofisiológicos.

\subsection{Eletrofisiologia}

As medidas de correntes foram feitas utilizando-se micropipetas de vidro, para conectar a célula em estudo ao sistema eletrônico (EPC-7 - Patch Clamp Amplifier- List Medical). As micropipetas foram feitas a partir de capilares de vidro borossilicato, estiradas em um estirador vertical de dois estágios e possuíam resistência entre 03 e $10 \mathrm{M} \Omega$, quando preenchidas com a solução descrita abaixo. As correntes iônicas foram medidas na configuração "whole-cell" da técnica de "patchclamp"(6). Nos experimentos, utilizamos, basicamente, dois protocolos de voltagens. No primeiro, após o selo ter sido estabelecido, a célula era submetida a um potencial de $-60 \mathrm{mV}$, constante ao longo do tempo (holding). No segundo, aplicou-se uma "rampa" de voltagem entre $-100 \mathrm{e}+100 \mathrm{mV}$, num tempo de dois segundos, obtendo-se, assim, uma relação correntevoltagem. As respostas de corrente foram armazenadas em um microcomputador, com auxílio de uma placa de conversão analógica e digital (Labmaster TL-1; Axon Instruments) e analisadas "off-line" por programas adequados (Pclamp 6.0; Axon Instruments).

\subsection{Soluções e Substâncias Químicas}

As células de Leydig foram banhadas por solução de Hank, cuja composição é a seguinte (mM): $\mathrm{NaCl}$ 145,0; $\mathrm{KCl} 4,6 ; \mathrm{CaCl}_{2}$ 1,6; $\mathrm{MgCl}_{2}$ 1,13; D-glicose 10,0; $\mathrm{NaHCO}_{3} 5,0$; HEPES 10,0. pH = 7,4 ajustado com $\mathrm{NaOH}$. A câmara foi perfundida, continuamente, com essa solução a um fluxo de aproximadamente $1 \mathrm{ml} / \mathrm{min}$.

A micropipeta foi preenchida com a seguinte solução (mM): $\mathrm{KCl} 150,0 ; \mathrm{MgCl}_{2}$ 1,0; HEPES 10,0; $\mathrm{CaCl}_{2} 0,775$; EGTA 5,0; ATP 3,0; pH ajustado para 7,4 com $\mathrm{KOH}$.

$\operatorname{ATP}\left(\mathrm{Na}_{2}{ }_{2}\right.$-ATP $)$ foi aplicado às células através de um sistema de superfusão com capilares de vidro (0,6 mm de diâmetro), posicionados a uma distância de aproximadamente $100 \mu \mathrm{m}$ sobre as células, e um fluxo ao redor de $70 \mu \mathrm{L} / \mathrm{min}$.

As drogas e sais utilizados foram adquiridos da Sigma Chemical Company (USA), as soluções foram feitas com água milli-Q (Millipore) e os experimentos realizados a $25 \pm 1^{\circ} \mathrm{C}$.

\section{3- RESULTADOS E DISCUSSÃO}

A Figura 1 mostra resultados de um experimento em que a célula teve sua voltagem fixada em- $60 \mathrm{mV}$ e o ATP foi aplicado nos tempos indicados. Como se pode observar, há o aparecimento de uma corrente orientada para dentro da célula, cuja amplitude é de- 
pendente da dose de ATP aplicada. As correntes possuem uma amplitude relativamente grande (600 pA de pico, com ATP $100 \mu \mathrm{M}$ ), principalmente se levarmos em consideração que as células de Leydig possuem diâmetro ao redor de $18 \mu \mathrm{m}$. O efeito do ATP é plenamente revertido, quando se retira a droga do banho. Outra observação interessante diz respeito ao padrão temporal da reposta. Aparentemente, existe um componente de dessensibilização, que é visto após o atingimento de um pico, num tempo de alguns segundos. Tal componente de dessensibilização é mais acentuado com concentrações maiores de ATP, como pode ser visto nos registros da Figura 1.

A Figura 2 mostra a relação corrente-voltagem para uma célula exposta a $100 \mu \mathrm{M}$ de ATP, situação em que se aplicou uma rampa de voltagem, entre \pm $100 \mathrm{mV}, 5$ segundos após a aplicação da droga, quando o efeito do ATP está em seu nível máximo. Observa-se, claramente, a presença de uma corrente com retificação para dentro, em potenciais negativos. $\mathrm{O}$ potencial de reversão da corrente está em torno de zero $\mathrm{mV}$. Esses dados nos levam a sugerir que se trata de uma corrente carregada por cátions, porém não seletivamente, e dependente de voltagem.

\section{4- CONCLUSÕES}

Esses resultados vêm confirmar, eletrofisiologicamente, a presença de receptores purinérgicos em células de Leydig, fato inédito na literatura. A ativação dos mesmos provoca o surgimento de uma corrente retificadora para dentro em potenciais hiperpolarizantes, demonstrando uma dependência de voltagem. O mesmo padrão de corrente já foi observado em várias outras células ${ }^{(7 / 10)}$. A amplitude da corrente é influenciada pela dose de ATP utilizada, visto que a corrente induzida por $100 \mu \mathrm{M}$ ATP é significativamente maior do que a ativada por $30 \mu \mathrm{M}$. Um outro aspecto que também aponta para isso é o aparente componente de dessensibilização que se torna mais evidente em doses maiores de ATP, o que está de acordo com o observado em outros tipos celulares ${ }^{(11)}$.

Todas as observações anteriores, somadas, nos levam à conclusão de que a provável classe de receptores presentes naquelas células seja a dos receptores P2X (canais catiônicos não seletivos), como mostrado para outras células ${ }^{(12,13)}$. Estudos complementares estão sendo realizados no sentido de se confirmar tal hipótese.

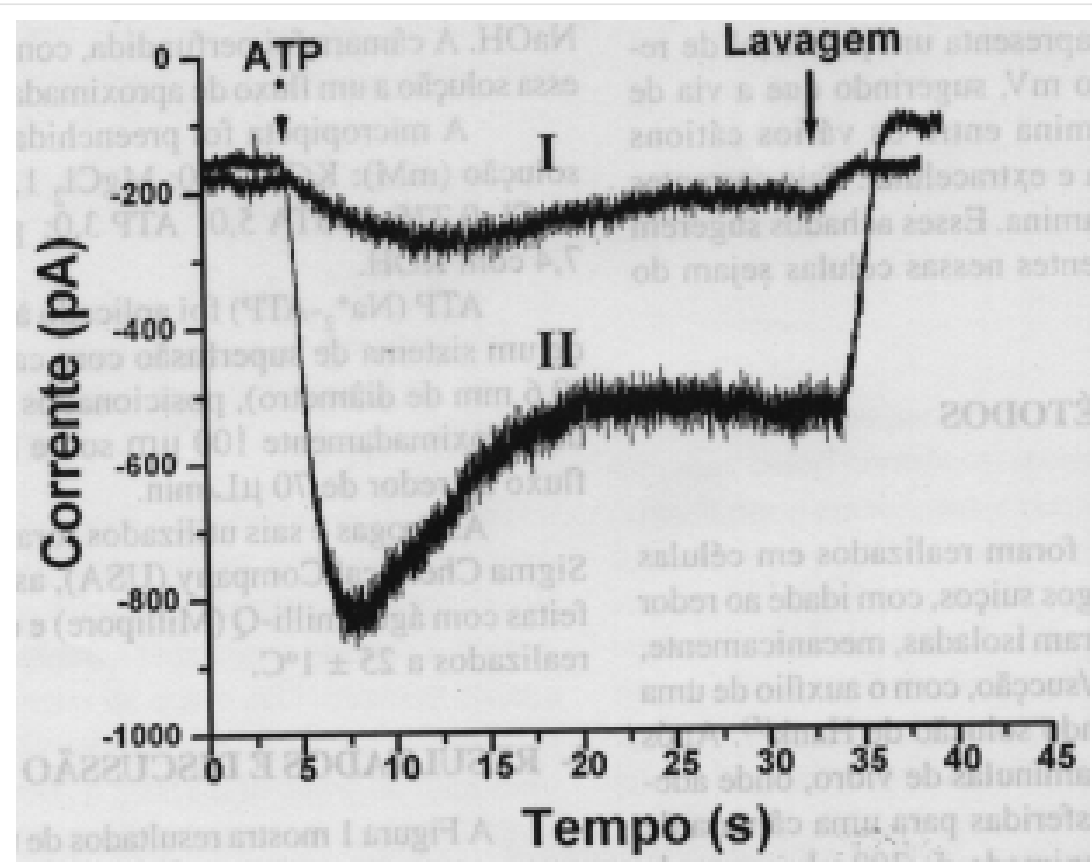

Figura 1: Correntes induzidas pelo ATP em células de Leydig. O potencial foi mantido em $-60 \mathrm{mV}$ e a aplicação da droga está indicada pelas setas. A resposta maior refere-se a $100 \mu \mathrm{M}$ de ATP (curva II) e a menor a $30 \mu \mathrm{M}$ (curva I). Os efeitos são revertidos pela retirada da droga do banho. 


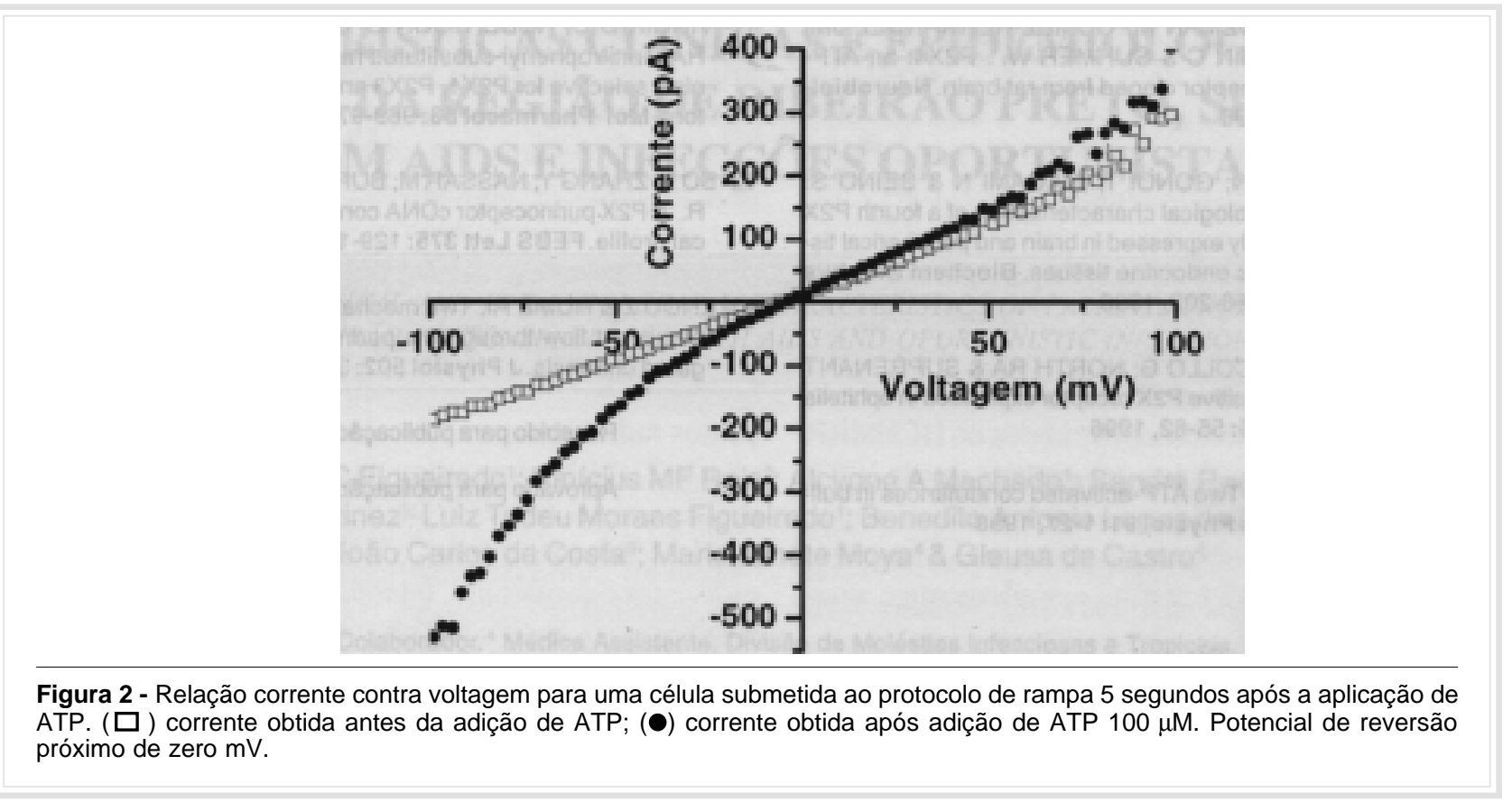

PONTELLI EP; AGUIAR JF \& VARANDA WA. Ionic currents induced by ATP in Leydig cells. Medicina, Ribeirão Preto, 33: 136-140, apr./june 2000.

ABSTRACT: Leydig cells are responsible for the production and secretion of testosterone. They are controlled by the Luteinizing Hormone (LH) in a process modulated by several substances. Recently, adenosine triphosphate (ATP) was found to be another modulator, acting through the activation of purinergic receptors. In this paper we used the patch clamp technique in order to detect and characterize the ionic currents induced by extracellular ATP in Leydig cells freshly isolated from mice testis. Addition of ATP to the bathing solution induces an inward current strongly rectifying at hyperpolarizing potentials. Such current is dependent on the doses of ATP and shows an apparent desensitization for ATP concentrations higher than $60 \mu \mathrm{M}$. The I-V plot reveals a reversal potential around zero $\mathrm{mV}$, indicating a non-selective cation current. These results confirm, from an electrophysiological point of view, the presence of purinergic receptors in Leydig cells, probably of the P2X type.

UNITERMS: Adenosine Triphosphate. Receptors, Purinergic. Patch-Clamp Techniques. Leydig Cells.

\section{REFERÊNCIAS BIBLIOGRAFICAS}

1 - FORESTA C; ROSSATO M; NOGARA A; GOTTARDELLO F; BORDON P \& DI VIRGILIO F. Role of P2-purinergic receptor in rat Leydig cell steroidogenese. Biochem J 320: 499504,1996

2 - BURNSTOCK G. Neural nomenclature. Nature (London) 229: 282-283, 1971

3 - RALEVIC V \& BURNSTOCK G. Receptors for purines and pyrimidines. Pharmacol Rev 50: 413-492, 1998
4 - PEREZ-ARMENDARIZ EM; NADAL A; FUENTES E \& SPRAY DC. Adenosine 5'-triphosphate (ATP) receptors induce intracellular calcium changes in mouse Leydig cells. Endocrine 4: 239247, 1996

5 - CARNIO EC \& VARANDA WA. Calcium-activated potassium channels are involved in the response of mouse Leydig cells to human chorionic gonadotropin. Braz J Med Biol Res 28: 813-824, 1995

6 - HAMILL OP; MARTY A; NEHER B; SAKMAN B \& SIGWORTH FJ. Improved patch-clamp techniques for high-resolution current recording from cell and cell free membrane patches. Pflugers Arch 391: 85-100, 1981 
7 - SOTO F; GARCIA-GUZMAN M; GOMEZ-HERNANDEZ JM HOLMAN M; KARSCHIN C \& SUHMER W. P2X4: an ATPactivated ionotropic receptor cloned from rat brain. Neurobiology 93: 3684-3688, 1996

8 - WANG CZ; NAMBA N; GONOI T; INAGAMI N \& SEINO S. Cloning and pharmacological characterization of a fourth $\mathrm{P} 2 \mathrm{X}$ receptor subtype widely expressed in brain and peripherical tissues including various endocrine tissues. Biochem Biophys Res Commun 220: 196-202, 1996

9- BUELL G; LEWIS C; COLLO G; NORTH RA \& SUPRENANT A. An antagonist-insensitive $P 2 X$ receptor expressed in ephitelia and brain. EMBO J 15: 55-62, 1996

10- FRIEL DD \& BEAN BP. Two ATP-activated condutances in bullfrog atrial cells. J Gen Physiol 91: 1-27, 1998
11- VIRGINIO C; ROBERTSON C; SURPRENANT A \& NORTH RA. Trinitrophenyl-substituted nucleotides are potent antagonists selective for $\mathrm{P} 2 \mathrm{X} 1, \mathrm{P} 2 \mathrm{X} 3$ and heteromeric $\mathrm{P} 2 \mathrm{X} 2 / 3$ receptors. Mol Pharmacol 53: 969-973, 1998

12- BO X; ZHANG Y; NASSAR M; BURNSTOCK G \& SCHOEPFER R. A P2X purinoceptor CDNA conferring a novel pharmacological profile. FEBS Lett 375: 129-133, 1995

13- ZHOU Z \& HUME RI. Two mechanisms for inward rectification of current flow through the purinoceptor P2X2 class of ATPgated channels. J Physiol 502: 353-364, 1998.

Recebido para publicaçâo em 20/01/2000

Aprovado para publicação em 03/05/2000 